\title{
Comparative efficiency of national health systems: cross national econometric analysis
}

\author{
David B Evans, Ajay Tandon, Christopher J L Murray, Jeremy A Lauer
}

\begin{abstract}
Objective To improve the evidence base for health policy by devising a method to measure and monitor the performance of health systems.

Design Estimation of the relation between levels of population health and the inputs used to produce health.

Setting 191 countries.

Main outcome measure Health system efficiency (performance).

Results Estimated efficiency varied from nearly fully efficient to nearly fully inefficient. Countries with a history of civil conflict or high prevalence of HIV and AIDS were less efficient. Performance increased with health expenditure per capita.

Conclusions Increasing the resources for health systems is critical to improving health in poor countries, but important gains can be made in most countries by using existing resources more efficiently.
\end{abstract}

\section{Introduction}

Policymakers have long been concerned with improving the performance of health systems. ${ }^{12}$ Reforms have targeted financing (for example, social health insurance and user charges), provision (for example, managed care, autonomous hospitals), stewardship (for example, regulation of the private sector, health legislation), and resource development (for example, retraining of staff). ${ }^{13-5}$ The impact of these reforms is increasingly being studied, ${ }^{67}$ but for the results to be useful to policymakers across different settings, studies need a consistent framework for assessing performance and a measurable indicator. ${ }^{8}$

The World Health Report 2000 defined three intrinsic goals of health systems-improving health, increasing responsiveness to the legitimate demands of the population, and ensuring that financial burdens are distributed fairly. ${ }^{9}$ For health and responsiveness, systems should improve levels and reduce inequalities. The report published first attempts to measure the attainment of these goals by 191 countries and considered how well countries were performing given their available resources. ${ }^{9}$ This paper describes the methods used for measuring and monitoring performance of health systems. Since improving health is the defining goal of the health system, we report performance in terms of that goal. Data sources have been given elsewhere. $^{10}$

\section{Methods}

Theory

Efficiency is defined as the ratio of the observed level of attainment of a goal to the maximum that could have been achieved with the observed resources. Normally, outputs are zero when inputs are zero. In health, however, health levels would not be zero if there were

\section{Healthy life expectancy}

Healthy life expectancy builds on the concept of life expectancy. Life expectancy is adjusted to allow for the fact that people live part of their lives in less than full health. These states are given weights between 0 and 1 to reflect their severity compared with full health (valued at 1). In rich countries, between 7 and 10 years are typically spent living in less than full health. Partly because of a longer life span, women spend more time in poor health than men do. In poor countries, people may spend over 20 years of their expected life span in poor health. Taking into account these weights, ill health and its consequences reduce healthy life expectancy by between 5 and 11 years across 191 countries.

no health expenditures-that is, no health systems. So to measure the contribution of the health system we have to determine what it achieves in excess of what would be achieved in its absence (the minimum). Accordingly, we define performance as the current level of population health, in excess of the estimated minimum, compared with the maximum achievable level of health given the inputs. Because of the similarity between performance and efficiency, we use the terms interchangeably.

Neither the maximum (frontier) nor the minimum levels of health are observable, so they have to be estimated. Two strategies could be used for estimating the maximum. One involves defining feasible interventions, identifying their costs and outcomes, and choosing those that maximise health for the available resources. This approach has not been widely used ${ }^{11} 12$ because of data limitations but is currently being pursued by the World Health Organization. ${ }^{13}$

The second approach, which we have used here, estimates the maximum from a sample of observed inputs and outcomes. This approach requires the relation between outcomes (population health) and inputs to be specified. We estimated this relation with a form of regression analysis that shows how health levels vary with inputs. The country with the highest health level, after controlling for inputs, is the most efficient. The maximum is the level of health the most efficient country would have produced at each observed combination of inputs. Efficiency of other countries is measured with respect to the maximum. Inefficiencies might be from wastage or because the most cost effective set of programmes or interventions are not used. Further details of the method are given on the BMJ's website.

\section{Data}

We estimated the efficiency of 191 countries from data for 1993-7. Population health was measured as healthy life expectancy (box). The health system input was health expenditure per capita measured in 1997 US dollars (adjusted for the cost of a generic basket of goods in different settings).
Editorial by McKee

Global Programme on Evidence for Health Policy, World Health Organization, 1211 Geneva 27, Switzerland

David B Evans director ad interim

Ajay Tandon fellow

Jeremy A Lauer

economist

Evidence and Information for Policy, World Health

Organization Christopher J L Murray executive director ad interim

Correspondence to: D B Evans evansd@who.int

BMJ 2001;323:307-10

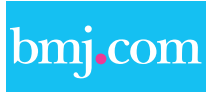

Further details of the methods and full results are available on the BMJ's website 
Levels of health are not solely affected by health systems. ${ }^{9}$ The most widely accepted other determinant is education, which is strongly associated with the health of both children and adults in developed and developing countries. ${ }^{14}{ }^{15}$ Educated people translate information and health services into health more effectively than uneducated people do. We used a summary indicator of educational attainment-average years of schooling in the adult population. ${ }^{10}$

We did not include income per capita because income is highly correlated with both health expenditure and education and complicates statistical estimation. Moreover, income does not directly contribute to health but acts through factors such as education, housing, and food intake. Inclusion of the part of income acting through mechanisms other than health expenditure and education made little difference to our results-the rank order correlation of efficiency scores was $>0.99$.

We estimated the minimum achievable health in the absence of a health system from observations on 25 countries before the existence of a modern health system (average year, 1908). Health levels were correlated mainly with literacy. We estimated the minimum health level for 1997 on the basis of current literacy rates as though the 1908 relation still applied. ${ }^{16}$

We generated an uncertainty interval as well as a point estimate of healthy life expectancy for each country. ${ }^{9}$ For all countries, we randomly drew observations from the uncertainty distributions and estimated efficiency and rank, repeating the procedure 1000

Table 1 Coefficient estimates used in calculation of maximum health, logged variables, 191 WHO member countries, 1993-7

\begin{tabular}{lccc} 
Coefficient estimate & Median & Mean & $\begin{array}{c}\text { Uncertainty interval } \\
\mathbf{( 9 5 \% )}\end{array}$ \\
\hline Health expenditure & 0.0089 & 0.0089 & 0.0087 to 0.0090 \\
\hline Average years of schooling & 0.0630 & 0.0630 & 0.0588 to 0.0673 \\
\hline Square of average years of schooling & 0.0217 & 0.0217 & 0.0203 to 0.0232 \\
\hline Constant & 4.0260 & 4.0269 & 4.0159 to 4.0397 \\
\hline
\end{tabular}

Table 2 Efficiency (performance) score and 80\% uncertainty intervals, highest and lowest ranking 10 countries and United Kingdom, 1993-7

\begin{tabular}{|c|c|c|c|c|}
\hline Rank & $\begin{array}{l}\text { Uncertainty } \\
\text { interval }\end{array}$ & Country & Performance & $\begin{array}{l}\text { Uncertainty } \\
\text { interval }\end{array}$ \\
\hline 1 & 1 to 5 & Oman & 0.992 & 0.975 to 1.000 \\
\hline 2 & 1 to 4 & Malta & 0.989 & 0.968 to 1.000 \\
\hline 3 & 2 to 7 & Italy & 0.976 & 0.957 to 0.994 \\
\hline 4 & 2 to 7 & France & 0.974 & 0.953 to 0.994 \\
\hline 5 & 2 to 7 & San Marino & 0.971 & 0.949 to 0.988 \\
\hline 6 & 3 to 8 & Spain & 0.968 & 0.948 to 0.989 \\
\hline 7 & 4 to 9 & Andorra & 0.964 & 0.942 to 0.980 \\
\hline 8 & 3 to 12 & Jamaica & 0.956 & 0.928 to 0.986 \\
\hline 9 & 7 to 11 & Japan & 0.945 & 0.926 to 0.963 \\
\hline 10 & 8 to 15 & Saudi Arabia & 0.936 & 0.915 to 0.959 \\
\hline 24 & 21 to 28 & United Kingdom & 0.883 & 0.866 to 0.900 \\
\hline 182 & 181 to 185 & South Africa & 0.232 & 0.209 to 0.251 \\
\hline 183 & 181 to 185 & Sierra Leone & 0.230 & 0.213 to 0.247 \\
\hline 184 & 181 to 186 & Swaziland & 0.229 & 0.205 to 0.255 \\
\hline 185 & 182 to 187 & Democratic Republic of the Congo & 0.217 & 0.198 to 0.235 \\
\hline 186 & 183 to 188 & Lesotho & 0.211 & 0.187 to 0.236 \\
\hline 187 & 186 to 188 & Malawi & 0.196 & 0.181 to 0.211 \\
\hline 188 & 187 to 189 & Botswana & 0.183 & 0.172 to 0.194 \\
\hline 189 & 185 to 189 & Namibia & 0.183 & 0.152 to 0.214 \\
\hline 190 & 190 to 190 & Zambia & 0.112 & 0.095 to 0.129 \\
\hline 191 & 191 to 191 & Zimbabwe & 0.080 & 0.057 to 0.103 \\
\hline
\end{tabular}

times with slightly different results. The reported efficiency estimate is the mean score for that country, and the uncertainty interval represents the range in which estimates fell, omitting the bottom and top $10 \%$. Rank was based on mean efficiency, and rank uncertainty intervals were generated in a similar manner.

\section{Results}

Table 1 gives the coefficient estimates used in the regression equation to determine efficiency. We investigated numerous specifications of the regression equation, but they gave stable estimates of efficiency and rank.

Table 2 shows the efficiency and ranks for the highest and lowest 10 performers and the United Kingdom. Estimated efficiency varies from 0.08 to nearly 1 , implying that although some countries may be close to their potential, others are not reaching anywhere near maximum levels of health. Figure 1 depicts the efficiency for all countries; the full results are available on the BMJ's website. ${ }^{9}$

Figure 2 shows that efficiency is positively related to health expenditure per capita, especially at low expenditure. Performance sharply increases with expenditure up to about $\$ 80$ (£53) per capita a year.

\section{Discussion}

Perceptions about the relative performance of health systems in different countries have been based on anecdote or case studies. For example, Sri Lanka and China are believed to have been efficient in producing health, ${ }^{17}{ }^{18}$ but our results show that both perform less well than other countries at similar levels of development. On the other hand, Oman performs extremely well-perhaps because it has reduced child mortality from 310 to 18 per 1000 live births over the past 40 years. $^{19}$

Our efficiency scores compare current population health levels with the maximum possible for observed levels of health expenditure and education in a country. This does not mean that $100 \%$ efficiency can be reached immediately. There will be time lags between some actions and their outcomes, and efficiency in many low performing countries is hampered by civil unrest or a high prevalence of HIV and AIDS (fig 1). Healthy life expectancy is reduced by up to 15 years in African countries with the highest prevalence of HIV, clearly restricting the ability of these systems to reach full efficiency in the short term.

\section{Validity of findings}

Although other non-health variables affect health (housing quality, environmental conditions, etc), relevant indicators are difficult to find or estimate for many countries. In addition, many are highly correlated with educational attainment, which we used because it functions as a broad measure of non-health inputs.

Omission of non-health variables reduces the estimates of efficiency. On the other hand, the measurement strategy biases estimates upward. The fact that five countries have efficiency scores $>0.97$ does not mean they can improve performance by nearly 3\%. It 


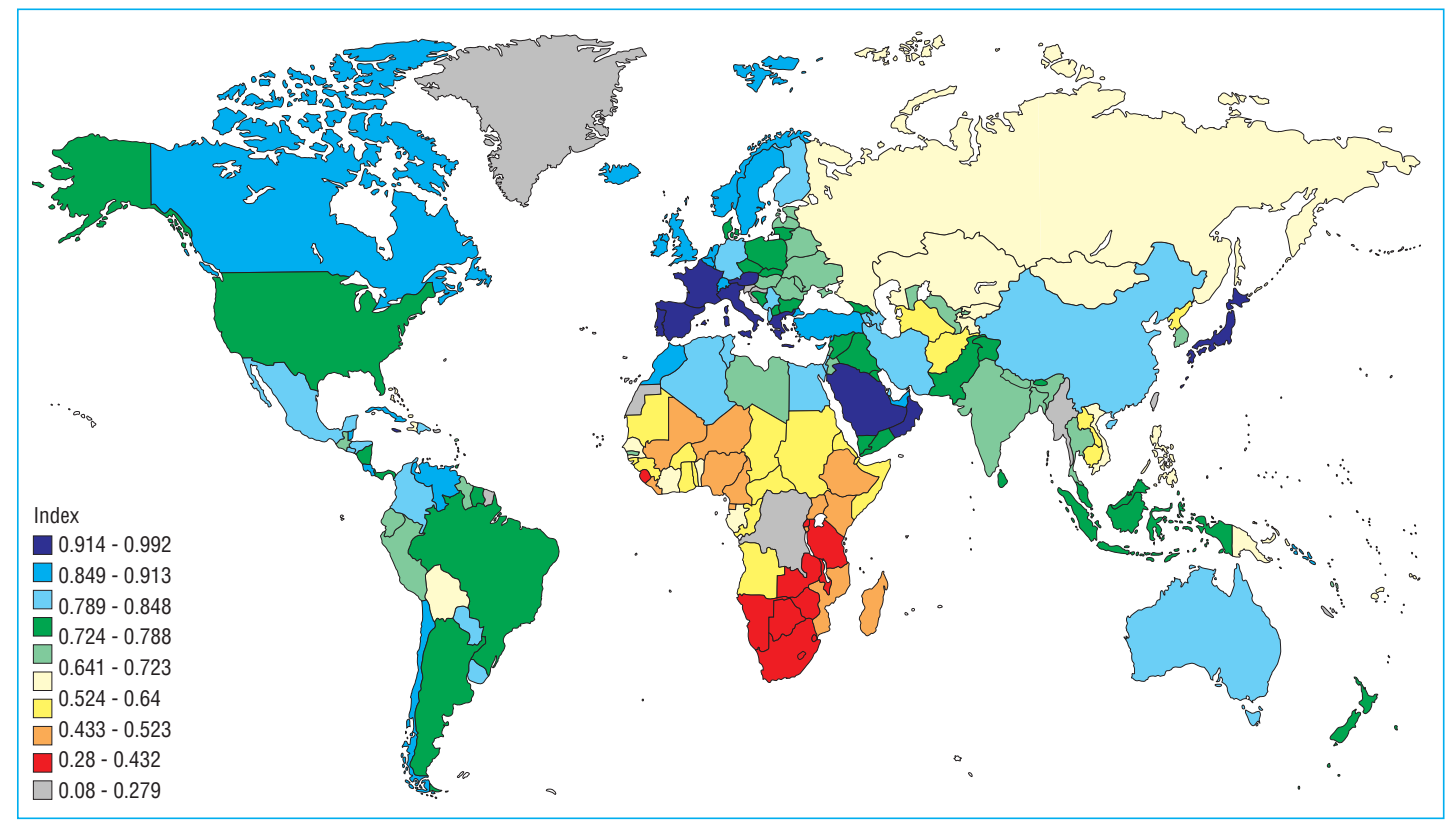

Fig 1 Global distribution of health system efficiency (performance) in maximising population health

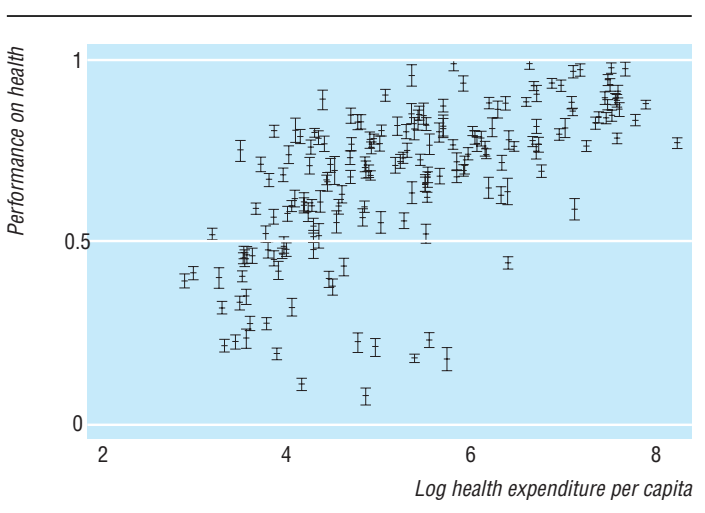

Fig 2 Efficiency (performance) in maximising population health versus health expenditure per capita, with $80 \%$ confidence intervals

means they could improve by $3 \%$ compared with the most efficient country, but we have no way of estimating the potential of the highest performer to become more efficient. Microlevel studies suggest the potential is there nevertheless.

\section{Reasons for inefficiency}

We found that efficiency is positively related to health expenditure per capita. Performance increased greatly with expenditure up to about $\$ 80$ per capita a year, suggesting it is difficult for systems to be efficient at low expenditure. There seems to be a minimum level of health expenditure below which the system simply cannot work well. We estimate it would cost just over $\$ 6$ bn a year $(<0.3 \%$ of global annual health expenditure) to increase health spending to this threshold in the 41 countries with lowest expenditures.

Despite the need to increase funds in poor countries, there is enough variation in efficiency at all levels of expenditure to suggest that using current resources better could improve health considerably. Reducing wastage is one way, but the studies of Tengs and Murray et al show that allocation of resources is also important. ${ }^{120}$ They argued that health in the
United States and sub-Saharan Africa could be greatly improved by reallocating available resources from interventions that are not cost effective to those that are more cost effective but not fully implemented.

Another possible reason for inefficiency is that goals other than health may be deemed important. The World Health Report 2000 recognised that countries may also wish to reduce inequalities or increase the responsiveness of the system. ${ }^{9}$ The efficiency of health systems in achieving all defined goals has been explored elsewhere. ${ }^{21}$ The analysis produced some changes in rank-for example, France was estimated to have had the most efficient system overall-but, in general, countries efficient in producing health are also efficient in producing other goals. ${ }^{21}$

\section{Future research}

Our conclusions are, of course, tentative. The quality of data across countries varies greatly, and only some of this is accounted for in our uncertainty analysis. Our main objective was to show that the attainment and efficiency of health systems can be measured and compared across countries and over time. Much can be done to improve the data and methods, and WHO is currently working on this with member countries and academic experts. We believe this is critical work for health policymakers considering reforms. Without the ability to measure the inputs and outputs of health systems, they cannot know if the reforms achieve their objectives.

The views expressed are solely those of the authors and do not necessarily represent those of WHO.

Contributors: DBE conceived the idea of applying the frontier production function approach to measuring the performance of health systems, supervised the performance research team, and wrote and revised the manuscript. AT, CJLM, JAL, and DBE developed, performed, and interpreted the econometric analysis. AT and CJLM developed the methods for uncertainty analysis, and AT and DBE put together the data required for the educational attainment variable. CJLM coordinated the World Health Report 2000 research teams, conceptualised the framework for analysing and measuring attainment and performance, and contributed to the development of the health 


\section{What is already known on this topic}

Evidence on the effectiveness of health system reforms is scarce

Studies have not used a consistent framework for specifying goals or measuring outcomes

\section{What this study adds}

Countries with the best levels of health do not always have efficient health systems

Efficiency is related to expenditure on health per capita, especially at low expenditure

The methods of measuring performance provide a basis for identifying policies that improve health and for monitoring reforms
5 Moore M. Public sector reform; downsizing, restructuring, improving performance. Geneva: World Health Organization, 1996 (Forum on health sector reform discussion paper 7).

6 Durham G, Kill B. Public health funding mechanisms in New Zealand. Aust Health Rev 1999:22:100-12.

7 Ron A. NGOs in community health insurance schemes: examples from Guatemala and the Philippines. Soc Sci Med 1999;48:939-50.

8 DeRosario JM. Healthcare system performance indicators: a new beginning for a reformed Canadian healthcare system. J Health Qual 1999;21:37-41.

9 World Health Organization. World Health Report 2000. Geneva: WHO, 2000.

10 Evans DB, Bendib L, Tandon A, Lauer JA, Ebener S, Hutubessy R, et al. Estimates of income per capita, literacy, educational attainment, absolute poverty, and income Gini coefficients for the World Health Report 2000. Geneva: World Health Organization, 2000. (Global programme on evidence for health Health Organization, 2000. (G
policy discussion paper No 7.)

11 Tengs TO, Adams ME, Pliskin JS, Safran DG, Siegel JE, Weinstein MC, et al. Five-hundred life-saving interventions and their cost-effectiveness. Risk Anal 1995; 15:369-90.

12 Murray CJL, Kreuser J, Whang W. Cost-effectiveness analysis and policy choices: investing in health systems. Bull World Health Org 1994;74:66374.

13 Murray CJL, Evans DB, Acharya A, Baltussen RM. Development of WHO guidelines on generalized cost-effectiveness analysis. Health Ecom 2000;9:235-51.

14 Caldwell JC. Education as a factor in mortality decline: an examination of Nigerian data. Pop Stud 1979;33:395-413.

system assessment framework. JAL estimated historical levels of health system attainment. All four authors revised the manuscript and approved the final version. Raymond Hutubessy, Yukiko Asada, and JAL researched historical income and education levels. Alan Lopez, Colin Mathers, Ritu Sadana, Josh Salomon, Omar Ahmad, and Doris Mafat estimated life expectancy and healthy life expectancy. Jean-Pierre Pouillier, Patricia Hernandez, and Chandika Indikadahena estimated health expenditure. Julio Frenk had a major input to the health system assessment framework. DBE is guarantor.

Funding: None.

Competing interests: None declared.

1 Maynard A, Bloor K. Health care reform: informing difficult choices. Int J Health Plann Manage 1995;10:247-64

2 Collins C, Green A, Hunter D. Health sector reform and the interpretation of policy context. Health Policy 1999;47:69-83.

Hussein AK, Mujinja PG. Impact of user charges on government health facilities in Tanzania. East Afr Med J 1997;74:751-7.

4 Feldman R. The ability of managed care to control health care costs: how much is enough? J Health Care Finance 2000;26:15-25.
15 Caldwell JC, Caldwell P. Education and literacy as factors in health. In: Halstead SB, Walsh JL, Warren KS, eds. Good health at low cost. New York: Rockefeller Foundation, 1985:181-5.

16 Evans D, Tandon A, Murray CJL, Lauer J. The comparative efficiency of national health systems in producing health: an analysis of 191 countries. Geneva: World Health Organization, 2000. (Global programme on evidence for health policy discussion paper No 29.)

17 Halstead SB, Walsh JA, Warren KS, eds. Good health at low cost. New York: Rockefeller Foundation, 1985

18 Hsiao W. What should macroeconomists know about health care policy? A primer. Washington, DC: International Monetary Fund, 2000. (IMF working paper.)

19 Ahmad OB, Lopez AD, Inoue M. The decline in child mortality: a reappraisal. Bull World Health Org 2000;78:1175-9.

20 Tengs TO. Dying too soon: how cost-effectiveness analysis can save lives. Dallas, TX: National Center for Policy Analysis, 1997. (NCPA policy report No 204.)

21 Tandon A, Murray CJL, Lauer J, Evans D. Measuring overall health system per(Global programme on evidence for health policy discussion paper No 30.) (Accepted 17 April 2001) formance for 191 countries. Geneva: World Health Organization, 2000

\section{Influence of variation in birth weight within normal range and within sibships on IQ at age 7 years: cohort study}

Thomas D Matte, Michaeline Bresnahan, Melissa D Begg, Ezra Susser

\begin{abstract}
Center for Urban Epidemiologic Studies, New York Academy of Medicine, 1216

Fifth Avenue, New York, NY 10029, USA

Thomas D Matte senior epidemiologist
\end{abstract}

continued over

BMJ 2001;323:310-4

\begin{abstract}
Objective To examine the relation between birth weight and measured intelligence at age 7 years in children within the normal range of birth weight and in siblings.

Design Cohort study of siblings of the same sex. Setting 12 cities in the United States.

Subjects 3484 children of 1683 mothers in a birth cohort study during the years 1959 through 1966. The sample was restricted to children born at $\geqslant 37$ weeks gestation and with birth weights of 1500-3999 g.
\end{abstract}

Main outcome measure Full scale IQ at age 7 years. Results Mean IQ increased monotonically with birth weight in both sexes across the range of birth weight in a linear regression analysis of one randomly selected sibling per family $(\mathrm{n}=1683)$ with adjustment for maternal age, race, education, socioeconomic status, and birth order. Within same sex sibling pairs, differences in birth weight were directly associated with differences in IQ in boys (812 pairs, predicted IQ difference per $100 \mathrm{~g}$ change in birth weight $=0.50$, $95 \%$ confidence interval 0.28 to 0.71 ) but not girls (871 pairs, $0.10,-0.09$ to 0.30 ). The effect in boys remained after differences in birth order, maternal smoking, and head circumference were adjusted for and in an analysis restricted to children with birth weight $\geqslant 2500 \mathrm{~g}$.

Conclusion The increase in childhood IQ with birth weight continues well into the normal birth weight range. For boys this relation holds within same sex sibships and therefore cannot be explained by confounding from family social environment.

\section{Introduction}

Many studies have shown that children born at low birth weight $(<2500 \mathrm{~g})$ have deficits in average intelligence test scores at school age. ${ }^{1}$ Within the low birth 